\title{
Rede de saberes entre educação inclusiva e saúde mental: a produção do cuidado e da aprendizagem na experiência profissional
}

\author{
Knowledge networks between inclusive education and mental \\ health: the production of care and learning in the professional \\ experience
}

Cristhiane Marques de Freitas ${ }^{1}$

Karla Rosane do Amaral Demoly²

Cláudia Rodrigues de Freitas ${ }^{3}$

\section{Resumo}

O artigo discute a composição das redes tecida a partir da experiência dos profissionais da educação inclusiva e da saúde mental que trabalham com crianças e adolescentes em circunstâncias de transtornos mentais e/ou sofrimento psíquico. A experiência educativa e clínica se fez presente em oficinas realizadas nos seguintes contextos: Atendimento Educacional Especializado das escolas, encontros de formação promovidos pelo Núcleo de Tecnologia Educacional Municipal e a experiência em saúde mental do Centro de Atenção Psicossocial da Infância e Adolescência no município de

\footnotetext{
1 Mestre em Cognição, Tecnologias e Instituições pela Universidade Federal Rural do Semi-Árido (UFERSA). Professora e Coordenadora do Núcleo de Tecnologia Municipal de Mossoró.

2 Pós-Doutora em Educação pela Universidade do Minho PT. Doutora em Informática na Educação pela Universidade Federal do Rio Grande do Sul. Professora do Departamento de Ciências Humanas da Universidade Federal Rural do Semi-Árido. Coordenadora do Programa de Pós-Graduação em Cognição, Tecnologias e Instituições e Coordenadora do Programa de Extensão Oficinando em Rede da UFERSA.

3 Doutora em Educação pelo Programa de Pós Graduação em Educação da Universidade Federal do Rio Grande do Sul (UFRGS). É Professora na linha de pesquisa Educação Especial, Saúde e Processos Inclusivos, no Programa de Pós-Graduação em Educação, na Universidade Federal do Rio Grande do Sul. Coordena o NEPIE (Núcleo de Estudos em Políticas de Inclusão Escolar).
} 
Mossoró/RN, Brasil. Tomamos como intercessores teóricos as proposições de Humberto Maturana, Francisco Varela, Mariza Eizirik, Paulo Amarante, entre outros, para pensar sobre como construimos sabedoria e conhecimento. Tal composição de perspectivas ganha corpo na observação das ações cognitivas dos profissionais envolvidos no trabalho educativo e clínico com crianças e adolescentes. Adotamos a metodologia em primeira pessoa, com seu caráter enativo, no qual conhecer é processo constitutivo de si e do mundo que conservamos no viver. As autonarrativas nas oficinas nos permitiram distinguir ideias e emoções recorrentes e em transformação, com destaque para as escritas nas quais os profissionais manifestaram o desejo de continuidade na realização de um trabalho coletivo.

Palavras-chaves: Rede. Educação Inclusiva. Saúde Mental. Biologia do Conhecer. Abordagem enativa.

\section{Abstract}

The article discusses the composition of networks woven from the experience of inclusive education and mental health professionals who work with children and adolescents in circumstances of mental disorders and / or psychological distress. The educational and clinical experience was present in workshops held in the following contexts: Specialized Educational Service in schools, training meetings promoted by the Municipal Center for Educational Technology and experience in mental health at the Psychosocial Care Center for Children and Adolescents in the municipality of Mossoró / RN, Brazil. We take Humberto Maturana, Francisco Varela, Mariza Eizirik, Paulo Amarante, among others, as theoretical intercessors to think about how we build wisdom and knowledge. This composition of perspectives takes shape in the observation of the cognitive actions of professionals involved in educational and clinical work with children and adolescents. We adopt the methodology in first person, with its enactive character, in which knowledge is a constitutive process of oneself and the world in which we live. The self-narratives and constructions of the workshops made it possible to distinguish recurring and changing ideas and emotions, with an emphasis on the writings in which the 
professionals expressed the desire for continuity in carrying out the collective work.

Keywords: Network. Inclusive Education. Mental Health. Biology of Knowing. Enactive approach.

\section{Introdução}

O presente artigo discute a composição de redes entre profissionais da educação inclusiva e da saúde mental através de uma experiência de pesquisa-intervenção. As redes estão referidas nas políticas públicas de educação e da saúde e mesmo nas estruturas construídas para organizar os sistemas e as atividades oferecidas para as comunidades.

Profissionais do Atendimento Educacional Especializado (AEE), do Núcleo de Tecnologia Educacional Municipal (NTM) e do Centro de Atenção Psicossocial da Infância e Adolescência (CAPSi) têm diante de si a tarefa de promover formas de aprendizagem e de cuidado.

Observamos diferentes circunstâncias no movimento de crianças e de adolescentes que são atendidos nos contextos da educação inclusiva e da saúde mental. O trabalho realizado por estudantes e pesquisadores do Programa Oficinando em Rede, da Universidade Federal Rural do Semi-Árido de Mossoró4 (UFERSA), permitiu a observação de que os profissionais não estabeleciam conversações entre si, portanto a composição de redes não se efetivava na experiência direta.

Oficinando em Rede é um programa de extensão voltado à promoção da saúde mental e da educação inclusiva, desenvolvido por estudantes e pesquisadores da UFERSA. Já o trabalho de uma das autoras interage com a formação de professores na Rede Municipal de Ensino de Mossoró, com ênfase na integração de tecnologias ao fazer pedagógico para qualificar a experiência da aprendizagem.

Nesse contexto, a pesquisa parte da seguinte questão: Como acontece a composição de redes e mudanças nas ações cognitivas de profissionais da

\footnotetext{
Informações no Site Oficinando em Rede. Disponivel em: $<$,https://oficinandoemrede.ufersa.edu.br/>..Acesso em 02 mai. 2020.
} 
educação inclusiva e da saúde mental que atendem a crianças e a adolescentes com transtornos mentais e/ou sofrimento psíquico?

Tomamos como intercessores teóricos Humberto Maturana e Francisco Varela (2011) - a Biologia do Conhecer, com ênfase para as noções de autopoiése e redes de conversação tecidas no entrelaçamento entre linguagens e emoções que configuram o modo humano de viver e conhecer. Os autores contribuíram para a compreensão sobre os processos cognitivos e afetivos e sobre as relações entre o viver e o conhecer, processos de coemergência eu-mundo, através de seus estudos sobre a autopoiése e a circularidade dos processos de viver-aprender-cuidar. Francisco Varela $(1990 ; 1988)$ esclarece sobre os processos enativos que compreendem a inscrição corporal da mente e a coemergência de si e do mundo. Apoia, ainda, a opção teórica e metodológica na qual empregamos a metodologia em primeira pessoa.

Gilbert Simondon (1989) nos ajuda a pensar sobre o conjunto que se organiza e faz interagir a sociedade que produzimos, as tecnologias e o entendimento sobre como construímos conhecimento. André Parente (2007) e Michel Callon (2004) permitem o aprofundamento sobre a potência da noção de rede na construção da reflexão sobre a experiência educativa e clínica. E, finalmente, Mariza Eizirik (2007; 2008) e Paulo Amarante (2010), entre outros cientistas, esclarecem sobre os processos educativos e clínicos e as formas de exclusão ou de inclusão que produzimos na convivência.

Essa composição de perspectivas ganha corpo e favorece a análise que conta com a realização de um conjunto de oficinas que permitem a livre expressão de ideias e emoções, construção coletiva de uma experiência que aproxima o trabalho clínico e pedagógico.

A tecitura de redes é o convite que fizemos aos profissionais para o estudo no qual acompanhamos processos de autoconstituição na experiência. Como procedimentos de pesquisa, abrimos espaços para a livre expressão sobre modos de cuidado e aprendizagem no atendimento clínico e pedagógico, inquietações que emergem no fazer profissional. Os desafios da inclusão educativa e social estão presentes no viver desses profissionais. 


\section{Rede teórica}

\section{Modos de auto-organização na composição das redes}

Para compreender as mudanças nos modos de fazer dos profissionais da educação inclusiva e da saúde mental, tomamos como referência a perspectiva da auto-organização, especialmente os estudos de Humberto Maturana e Francisco Varela (2011), como já referimos. Os conceitos de autopoiése, organização e mudança estrutural são essenciais para a ampliação do entendimento sobre processos presentes no modo de viver e conhecer dos seres humanos. Os cientistas apresentam a construção autopoiética dos seres vivos, o que entre nós humanos implica pensar na contínua busca de manutenção da organização do sistema vivo e nas contínuas mudanças estruturais na convivência. Quando aborda a organização e conservação da vida humana, Humberto Maturana esclarece que vida, sabedoria e conhecimento humanos se conservam nas redes de conversações, tecidas no contínuo entrelaçamento entre os diferentes modos de agir na linguagem e as emoções que os sustentam. "Tudo o que nós, os seres humanos, fazemos como tal, o fazemos nas conversações. E aquilo que não fazemos nas conversações, de fato, não o fazemos como seres humanos" (MATURANA, 1999, p. 47).

Dessa forma, estamos, a cada instante, conservando modos de viver e de conhecer e há estreita articulação entre os processos do viver e do conhecer com as emoções. Estas são premissas fundamentais para nossa análise, ao buscarmos compreender o tecer de uma rede para favorecer a aprendizagem e o cuidado na educação inclusiva e na saúde mental. Ambiente e sujeito se transformam no percurso de construção das experiências, na convivência. Maturana e Varela construíram o conceito de autopoiése que significa autoprodução. O sistema autopoiético é, ao mesmo tempo, produtor e produto: “os seres vivos são autônomos, isto é, autoprodutores - capazes de produzir seus próprios componentes ao interagir com o meio: vivem no conhecimento e conhecem no viver" (MATURANA e VARELA, 2011, p. 14).

A abordagem da Biologia do Conhecer considera que a realidade precisa ser posta entre parênteses, portanto, as questões que estudamos interagem com o olhar e com o modo de explicar do observador. "Não precisamos fazer tudo o que podemos fazer", esclarece Maturana, durante curso de formação no 
qual um dos autores esteve presente. Implica compreender que criando modos de viver na linguagem, sempre temos os sonhos e emoções humanas que funcionam como suporte de nossas construções.

Observador e fenômeno se transformam no fazer da pesquisa-intervenção. Temos, neste estudo, a configuração de um olhar que observa e distingue os movimentos da cognição inventiva dos profissionais da educação inclusiva e da saúde mental. Os seres vivos são determinados por sua estrutura; o que nos acontece depende da estrutura determinante. Maturana (2006) explica que a interação com o meio possibilita novos acoplamentos de seres linguajantes. "A linguagem é um modo de viver juntos num fluir de coordenação consensual de coordenações consensuais de comportamentos, e é como tal um domínio de coordenações de coordenações de ações" (MATURANA, 2006, p. 178). Portanto, acompanhar mudanças nas condutas de profissionais que têm como objetivo promover cuidado e aprendizagem nos ambientes da educação e da saúde mental significa pensar que os modos de tecer redes dependem da interação, da convivência, dessa forma, as estruturas são ontogenéticas, são aprendidas.

$\mathrm{O}$ encontro, as construções e a escuta atenta e acolhedora de autonarrativas funcionam como caminho de pesquisa que favorece mudanças na emoção. Se mudamos nossa emoção, mudamos nossas coordenações de ações nos processos educativos e nas práticas de cuidado construídas na saúde mental.

Nize Pellanda (2009) nos instiga a pensar a cognição como conjunto de interações de seres que se auto-organizam diante dos ruídos vividos em ambientes solidários.

De um lado, precisamos de um ambiente pedagógico que favoreça a autoria, a autoconstrução e a autorreflexão e, por outro, pensar em ambientes solidários, de cooperação, que levem em conta a rede como modelo de vida e a necessidade de proporcionar processos auto-organizativos nos sujeitos (PELLANDA, 2009, p. 52)

Compreender os processos de auto-organização tem profundas implicações para o trabalho de promoção da aprendizagem na educação inclusiva e para o cuidado na saúde, ao resgatar a autonomia constitutiva dos 
seres que vivem espontaneamente processos sistêmicos de conservação da vida. Aprender é uma experiência humana criativa, singular e intransferivel. Ao mesmo tempo, aprender ocorre na convivência e as possibilidades e dificuldades são integrantes do viver-conhecer. Precisamos pensar sobre como promover modos de aprender e cuidar, como efetivamente a tecitura das redes acontecem, redes tão presentes nos documentos das políticas dirigidas à educação inclusiva e à saúde mental.

Mariza Eizirik ajuda a refletir sobre o fazer com o outro que ocorre sempre no lidar com a diferença. A autora pergunta: "Por que a diferença incomoda tanto?" (2008, p. 19) e convida a pensar a diferença como incômodo visível e invisivel que perturba e permite ultrapassar limites, quando promove a reconstrução de novos olhares e percepções.

Nesse exercício de reinvenção do fazer profissional, lidando com a diferença na rede que se tece entre profissionais das instituições de educação inclusiva e da saúde mental, Eizirik discute sobre os processos de inclusão e exclusão que se fazem presentes em nossa sociedade, onde as estruturas que se tecem no trabalho educativo e/ou clínico são ainda altamente competitivas: "Estamos em meio a um processo de gestação. Buscamos novas formas, contornos, possibilidades, com todas as alegrias e sofrimentos que o acompanham" (EIZIRIK, 2008, p. 23). Desenvolver a experiência em perspectiva inclusiva não é uma tarefa fácil, não existe receita ou manual pronto. Implica um movimento de transformação de si mesmo, pois confronta com toda uma tecitura social que não mais se sustenta, onde a competitividade, a negação da legitimidade da presença do outro na diferença se faz ainda muito atual.

Em um processo de transformação, o movimento pela educação inclusiva emergiu de lutas, ações e conquistas de leis na busca por transformações no trabalho educativo. A Constituição Federal de 1988 estabelece igualdade de condições de acesso e permanência na escola e afirma que é dever do Estado garantir "atendimento educacional especializado [...] preferencialmente na rede regular de ensino" (BRASIL, 1988). Portanto, as ações da pesquisa acontecem em um cenário no qual é essencial construirmos 
espaços para a reflexão e a escuta dos profissionais diretamente envolvidos no fazer da educação e da saúde mental.

O AEE é um serviço da Educação Especial que perpassa todas as modalidades de ensino da Educação Básica e Superior. Tem como sujeitos a serem atendidos, alunos com deficiência física, deficiência intelectual, surdez, cegueira, baixa visão, surdocegueira, e/ou sujeitos com transtornos globais do desenvolvimento e altas habilidades (BRASIL, 2008).

No âmbito da inclusão escolar, a política educacional brasileira orienta que a educação de alunos com deficiência deve ser realizada no ensino regular. A Lei 13.146, de 2015, estabelece o direito à educação inclusiva das pessoas com deficiência em todos os niveis de ensino e ao longo de toda a vida. (BRASIL, 2015).

$\mathrm{Na}$ construção de processos inclusivos, Eizirik (2007) enfatiza que somos diferentes e que a diferença oportuniza a possibilidade do crescer com o outro, o cultivar contínuo de novos olhares e experiências. O cultivar dessa relação com o outro pode transcorrer numa construção recíproca de uma ética com condutas de acolhimento, tecidas na confiança, respeito e amor.

Nesse viver com a diferença, Cláudia Freitas (2011) aborda que o conhecimento é construído numa relação recíproca de escuta e atenção. A autora alerta sobre as possibilidades da exclusão e/ou inclusão vividas na escola:

\footnotetext{
Podemos reconhecer aqui um campo fértil para a exclusão das possibilidades de aprender na escola. Excluída deste processo, a criança fica prejudicada em sua possibilidade de pensar e estabelecer atividades de atenção dentro da escola. Devemos pensar que a relação pedagógica não é dada a priori, mas vai sendo construída aos poucos. Não passamos a ser aluno ou professor porque nosso nome consta em uma lista de chamada. Aprendemos quando somos escutados e podemos escutar. Aprendemos de quem elegemos, de quem escolhemos para tal. Aprendemos quando confiamos no outro, em nós e no espaço de relação que se oferece. Aprendemos quando somos escutados e atendidos (FREITAS, 2011, p. 57).
}

Quando nos propomos a aprender com o outro é porque percebemos que existe nessa relação a reciprocidade da escuta e o compromisso no compartilhar os saberes construídos, as perguntas, as inquietações. Na escola, o fazer com o outro e as ações coletivas possibilitam e fortalecem o 
operar de mudanças e construções subjetivas. Este modo de fazer acontece quando na escola nós professores nos permitimos cultivar o desejo de disseminar a inclusão, reconhecendo no diferente um campo de possibilidades para a aprendizagem.

Na saúde mental, muitos movimentos também aconteceram e envolvem mudanças nos modos de lidar com a diferença nas dimensões psíquica e coletiva, ou nos modos de lidar com a loucura. Amarante (2010) apresenta os movimentos da reforma psiquiátrica, tendo a desinstitucionalização como desospitalização. Este movimento tem como protagonista o italiano, médico e psiquiatra Franco Basaglia, quando percebeu que apenas a psiquiatria não conseguiria dar conta de um fenômeno tão complexo como a loucura. E que a desinstitucionalização é um processo prático de desconstrução, um processo de invenção de novas realidades (AMARANTE, 2010, p. 104).

Em busca desses novos olhares e recriação da experiência, as ações da sociedade e dos profissionais da educação e da saúde foram primordiais na mudança progressiva contra a prática do manicômio, bem como a constituição da Lei Antimanicomial $\mathrm{n}^{\circ}$ 10.216, de 2001 que possibilitou a construção alternativa de práticas terapêuticas, serviços assistenciais, reduzindo o tempo de internação nos hospitais psiquiátricos. A mudança implica criar práticas de inserção dos sujeitos no meio familiar e social, como proposta de ressocialização/reabilitação.

Com base no processo de desinstitucionalização, chegamos à criação do primeiro Centro de Atenção Psicossocial (CAPS) no Brasil, inaugurado em 1986 na cidade de São Paulo (BRASIL, 2004). Os serviços do CAPS são destinados ao acolhimento de pessoas com transtornos mentais, buscando a integração e reintegração no meio social, cultural e familiar, enfatizando a autonomia.

Nessa direção, a pesquisa se organiza buscando a ampliação do nosso entendimento sobre como acontecem os movimentos da cognição inventiva na tecitura da rede entre os profissionais da educação inclusiva e da saúde mental. 


\section{A tecitura de redes e o conjunto constituído pelas sociedades, o pensamento humano e as tecnologias}

Para pensar sobre a rede que se tece neste encontro de profissionais com as tecnologias, buscamos também os estudos de Gilbert Simondon (1989). Filósofo e tecnólogo francês, Simondon foi reconhecido como o filósofo da técnica com notáveis conhecimentos em mecânica, eletrônica, hidráulica e termodinâmica. Estudioso dos processos de individuação humana e da individualização dos seres técnicos, suas construções contribuíram para a nossa pesquisa, ao buscar compreender os modos de atualização dos profissionais no processo de individuação que envolve educação e saúde mental. Para Simondon (1989), a invenção técnica e a individuação humana interagem com sonhos e projetos humanos, modos de conceber a vida e agir sobre nós mesmos e sobre o coletivo. Há um conjunto técnico constituído pelas sociedades, o pensamento humano e as tecnologias, "o ser técnico evolui por convergência e por adaptação a si; ele se unifica interiormente segundo um princípio de ressonância interna" (SIMONDON, 1989, p. 20). Já o ser humano vive processos de individuação psíquica e coletiva, vive o seu devir histórico e mudanças em torno da conservação do viver.

Como ação inovadora e desafiante, a pesquisa proporcionou a aproximação entre os saberes pedagógicos e clínicos para poder discutir e compreender como a rede se constitui no cotidiano das práticas. Para compreender a noção de rede, destacamos Michel Callon (2004) que nos permitiu refletir sobre os modelos de difusão do conhecimento com atores ativos e passivos, processos que se opõem ao modelo em rede. Na rede, as ideias circulam, conectam experiências, estão vivas e suscitam possiveis reações. André Parente $(2004$; 2007) nos ajudou a pensar sobre a experiência de recriação do próprio viver-conhecer:

Essas características das redes podem ser aplicadas aos organismos, às tecnologias, aos dispositivos, mas também à subjetividade. Somos uma rede de redes (multiplicidade), cada rede remetendo a outras redes de natureza diversa (heterogênese) em um processo auto-referente (autopoiesis). O sujeito é um sistema autopoiético e, como todo sistema autopoiético definido por Varela e Maturana, ele se organiza como uma rede auto-referente, que regenera, continuamente por suas interações e transformações, a rede que o produziu, e se 
constitui como sistema ou unidade concreta no espaço em que existe, especificando o domínio topológico no qual existe como rede. A subjetividade é, como a cognição, o advento, a emergência (enação) de um afeto e de um mundo a partir de suas ações no mundo" (PARENTE, 2007, p. 101).

O tecer da rede de saberes com os profissionais da educação e saúde mental engajou profissionais na construção e reflexão sobre modos de aprender e cuidar. A metodologia na pesquisa propôs-se a construir espaços coletivos de discussão, negociação, caminhos de conhecimentos acessíveis e abertos. Inspiradas em Callon, podemos dizer que a ciência se reaplica no saber-fazer com a experiência que se transforma, combina e se adapta às singularidades. A produção de ideia se opõe à passividade do fazer tradicional. "Uma ideia que não circula, que não é discutida, desmembrada, recomposta, é uma ideia morta, sem futuro" (CALLON, 2004, p.70).

Parente compreende a rede em dois movimentos, como hierarquização social que reflete apenas a pluralidade do pensamento e como ação: "pensar é pensar em rede" (PARENTE, 2007, p.101), movimento híbrido que promove novas subjetividades. A tecitura da rede envolveu um conjunto formado pelos sonhos e pensamentos dos profissionais, as ações cotidianas nos contextos da educação inclusiva e da saúde mental e as relações com as comunidades/sociedades que conservamos com nossas ações.

Vivemos na sociedade uma busca pelo desenvolvimento tecnológico que ainda se encontra distante da compreensão de que há relação entre tecnicidade e modos de viver. As diferentes tecnologias sempre se fazem presentes nos percursos de conhecimento e podem ampliar as possibilidades nas atividades na área da saúde e da educação.

Neste estudo, buscamos conectar a rede educação inclusiva e saúde mental com o viver-fazer dos profissionais, integrando as tecnologias. Nas oficinas, não estamos a lidar apenas com equipamentos, computadores, pois sabemos que na convivência e no tecer da rede, é crucial cuidar do modo como estabelecemos as relações. Assim, foi possivel discutir uma rede de saberes que proporcionou a circularidade do conhecimento, sabedoria entre profissionais da educação e da saúde mental que convivem nos espaços das 
escolas e do Centro de Atenção Psicossocial da Infância e Adolescência (CAPSi).

\section{Metodologia}

A pesquisa realizada é de natureza qualitativa, com delineamento na pesquisa-intervenção, com emprego de oficinas que favoreceram a construção de uma experiência com os sujeitos participantes.

O estudo desenvolveu-se nas instituições que atendem a crianças e a adolescentes nos contextos da educação inclusiva e da saúde mental e em um núcleo que trabalha na formação de professores municipais de Mossoró/RN.

Importante ressaltar como fizemos a escolha das instituições. $\mathrm{Na}$ Educação, convidamos quatro escolas do ensino fundamental da rede municipal de ensino de Mossoró/RN, estrategicamente localizadas nos quatro bairros que cruzam os pontos geográficos (norte, sul, leste e oeste) da zona urbana da cidade. Todas as escolas possuem Atendimento Educacional Especializado com professor que tem como principal ação o atendimento em sala de recursos multifuncionais. Os alunos destes professores também são atendidos no CAPSi. O Núcleo de Tecnologia Municipal de Mossoró está localizado na zona urbana da cidade e é a segunda unidade da educação participante da pesquisa, por ser encarregado de propor a formação de professores para a integração de tecnologias e a promoção da aprendizagem nas escolas. Na área da saúde mental, escolhemos o Centro de Atenção Psicossocial da Infância e da Adolescência de Mossoró, isto porque uma das autoras do estudo coordena um programa de extensão universitária nessa instituição, desde onde fomos delineando a pergunta que desencadeia a pesquisa.

O CAPSi é a única instituição no município que atende a crianças e a adolescentes que necessitam de cuidados na saúde mental e que, infelizmente, muitas vezes se afastam da experiência da aprendizagem escolar.

Participaram da pesquisa sete profissionais que trabalham no Atendimento Educacional Especializado, compondo o quadro atual dos funcionários das quatro escolas selecionadas da rede municipal; três professores-formadores que integram o quadro de funcionários do Núcleo de 
Tecnologia Municipal de Mossoró e quatro profissionais do Centro de Atenção Psicossocial da Infância e da Adolescência (assistente social, educador-físico, psicopedagogo e fonoaudióloga).

Para esta pesquisa foram realizadas seis oficinas que duraram, em média, duas horas cada, ocorrendo durante um período de quatro meses. Antes do início das oficinas, fizemos visitações a cada uma das instituições e iniciamos a composição de diários de bordo, com registros sobre como os profissionais percebiam as circunstâncias de crianças e de adolescentes atendidos pelas diferentes instituições de educação e de saúde mental.

As oficinas ocorreram nos três ambientes - CAPSi, NTM e AEE -, pois seguiamos as pistas indicadas pelos participantes, os quais manifestaram interesse em conhecer o trabalho uns dos outros. Para resguardar a identidade dos sujeitos participantes da pesquisa, consideramos as sugestões deles que indicaram para si mesmos nomes fictícios.

Destacamos que durante o tecer da escrita, apresentaremos a experiência contando com escritos construídos pelos profissionais para apresentar suas unidades institucionais; excertos das autonarrativas com nomes fictícios; documentos elaborados pela Unidade Federativa, Ministério da Saúde e Ministério da Educação (leis, portarias, decretos, resoluções e manual de orientação). Buscamos as recorrências e as transformações que nos permitiram observar e discutir os nós na tecitura de redes que promovem modos de aprender e de cuidar nos contextos da educação inclusiva e da saúde mental. O termo "nó" foi construído na oficina pelos profissionais do AEE, NTM e CAPSi, para representar os pontos importantes na construção da rede.

O projeto de pesquisa foi aprovado pela Comissão Nacional de Ética em Pesquisa - CONEP, sob o parecer de $n^{\circ} 2.292 .865$, em 22 de setembro de 2017.

Para registrar os momentos e as etapas na realização da pesquisa, recorremos a alguns equipamentos e ferramentas: câmera fotográfica, filmadora e gravador de áudio. Esses equipamentos foram utilizados durante o percurso das oficinas e nas conversações ocorridas em visitas às instituições, possibilitando o captar detalhado do movimento e sinais sonoros produzidos 
nas imagens. O registro do diário de campo pelas pesquisadoras contribuiu na observação do percurso das oficinas e das construções presentes nas visitas às instituições.

Salientamos que utilizamos a escrita em primeira pessoa, com seu caráter enativo, compreendendo corpo e mente conectados como processos disparadores de autoconstituição no viver-fazer das oficinas. A abordagem enativa nas ciências cognitivas que adotamos na pesquisa é proposta por Francisco Varela e colaboradores, para fazer frente ao modelo de representação como explicativo para a questão sobre como acontecem as experiências do conhecimento e da vida humana (VARELA, 1988; VARELA et al. 1992). Diferentemente da abordagem representacionista, para a qual sujeito e mundo preexistem ao operar dos sujeitos cognitivos, a perspectiva enativa afirma que conhecer envolve uma inscrição corporal da mente, isto é, mundo e mente emergem no transcurso de uma experiência, pelas ações diversas realizadas do ser humano no mundo. Nesta perspectiva, como procedimentos metodológicos da pesquisa, temos a inclusão do pesquisador no sistema que observa e um trabalho que foi realizado com a discussão das autonarrativas e produções dos participantes.

As autonarrativas foram gravadas, filmadas e escutadas nas diferentes ações na linguagem que aconteceram durante as oficinas. Os participantes, incluindo aqui as pesquisadoras, experienciam um processo metacognitivo que compreende a inseparabilidade entre conhecer e autoconstituir-se no percurso de uma pesquisa.

Como Varela (1990) esclarece, a experiência do humano é primordial para o processo de construção de si mesmo no construir da realidade. O olhar das pesquisadoras faz movimentar a atenção para os movimentos da cognição inventiva dos profissionais da educação inclusiva e da saúde mental, nas suas construções e autonarrativas que acontecem com integração de diferentes tecnologias.

$\mathrm{Na}$ pesquisa, percorremos o caminho explicativo da objetividade entre parênteses, que surge no momento em que perguntamos pelo observar e pelo observador, no momento em que assumimos a Biologia do Conhecer. 
Maturana (2002) coloca a objetividade-entre-parênteses no processo de explicar:

\begin{abstract}
Não quero dizer com isso que não existem objetos, nem que não posso especificar um certo domínio de referência que trato como existindo independente de mim. Quero dizer que, colocando a objetividade entre parênteses, me dou conta de que não posso pretender que eu tenha a capacidade de fazer referência a uma realidade independente de mim, e quero me fazer ciente disto na intenção de entender o que ocorre com os fenômenos sociais do conhecimento e da linguagem, sem fazer referência a uma realidade independente do observador para validar meu explicar (MATURANA, 2002, p. 45).
\end{abstract}

A inseparabilidade entre cognição e experiência está relacionada à inseparabilidade do corpo e mente.

A construção teórico-metodológica da pesquisa esteve alicerçada especialmente nos estudos que Humberto Maturana realizou com Francisco Varela (2011) que resultaram na construção do conceito central da Biologia do Conhecer - autopoiése. Contamos, ainda, com o aprofundamento dos estudos de Humberto Maturana (1999; 2002; 2006; 2014) e com os trabalhos nos quais Francisco Varela esclarece sobre a inscrição corporal da mente humana (1988; 1990; 2003). Estes autores nos oferecem ferramentas importantes para pensar sobre as ações cognitivas dos participantes da pesquisa. Para Varela (1990), o ser vivo é um ser cognitivo, isto é, um ser produtor de sentido que constitui o mundo e a si a partir do acoplamento estrutural com o meio. $\mathrm{O}$ meio não é determinante; ele pode promover perturbações internas. As oficinas favoreceram o desencadeamento de redes de conversações permitindo a observação de mudanças nas condutas - ideias, gestos, emoções, forjados na experiência.

Destacamos o princípio da auto-organização, lógica circular consagrada na segunda Cibernética pelos estudos de Von Foerster (2003), físico e filósofo que esclarece sobre a autorregulação nos processos de conhecer e viver humanos. O autor propõe a passagem dos sistemas observados para os sistemas observantes, nos quais o observador pesquisador está implicado no processo do conhecer.

Henri Atlan ajuda a compreender as possibilidades de auto-organização dos profissionais no conectar da rede de saberes-fazeres na saúde mental e na 
educação. Sua teoria da complexificação pelo ruído aponta que na interação indivíduo-meio as perturbações (ruídos) não são determinantes, mas são elementos importantes e disparadores de processos auto-organizadores (ATLAN, 1992) .

Rodas de conversa foram construídas pelos pesquisados e as pesquisadoras nas oficinas, e proporcionaram, inicialmente, maior aproximação e conhecimento entre os participantes. Já na primeira oficina houve interesse em conversar sobre os fazeres profissionais pedagógicos e clínicos. Maraschin (2004) explica o percurso da pesquisa-intervenção na perspectiva da biologia do conhecer:

O percurso argumentativo explicitado, auxiliado por alguns conceitos da Biologia do Conhecer, pode tornar explícito como o pesquisar se produz em uma rede de conversações que também institui, no mesmo ato, a intervenção e a co-responsabilidade ética de autorias de si e do mundo (MARASCHIN, 2004, p. 106).

A pesquisa-intervenção compreende um trabalho que emerge de uma experiência, portanto não vamos a campo coletar dados. De dentro de uma experiência, identificamos inquietudes e, desde aí, há mobilização na ação de pesquisar. Nesse operar, nos envolvemos no fazer inventivo com os participantes, buscamos acompanhar como acontece a tecitura de rede entre profissionais da educação inclusiva e da saúde mental. Compreendemos a pesquisa como uma construção de aprendizagem coletiva, na qual agimos e intervimos juntos no processo do conhecer.

\section{Resultados e Discussões}

Modos de coordenar ações na rede entre educação inclusiva e saúde mental

Sabedoria e conhecimentos emergem na experiência, nas explicações autonarradas no viver a composição da rede construída com os profissionais do Atendimento Educacional Especializado, dp Núcleo de Tecnologia Educacional Municipal e do Centro de Atenção Psicossocial da Infância e Adolescência. 
No primeiro encontro da oficina, os participantes teceram autonarrativas e algumas foram recorrentes, o que nos ajudou na reflexão sobre os motivos de aceitar participar da pesquisa e sobre como compreenderam o convite do conectar das redes Educação e Saúde Mental.

\begin{abstract}
A gente precisa de uma equipe multidisciplinar, porque a demanda é muito grande, né, encontramos lá na escola alunos com dislexia, alunos com deficiência, aluno com tudo o que é transtorno e a gente não sabe o que fazer, a gente fica com as mãos na cabeça, então, eu busco ajuda e por isso estou aqui (Excerto n ${ }^{\circ}$ 01, Clara (AEE), 26/09/2017).

Eu tenho vontade de conhecer o CAPSi, ver a ação de vocês. Essa foi a curiosidade que me fez participar desta pesquisa. Percebo que se busco a mudança, ela está em mim. Eu acho que foi isso também o que me trouxe até aqui (Excerto $\mathrm{n}^{\circ}$ 02, Alice (NTM), 26/09/2017).
\end{abstract}

Percebemos nas autonarrativas dos participantes que eles já conviviam com a necessidade de constituir encontros de saberes entre as redes Educação e Saúde Mental. Foi possivel compreender o interesse que partia da necessidade profissional de desenvolver um trabalho colaborativo entre as instituições. Neste encontro inicial, os participantes compartilharam suas inquietudes e indicaram possibilidades para a continuidade das oficinas. Ressaltaram a necessidade de se conhecerem melhor para, quem sabe, poder fortalecer o trabalho que realizam.

Para Maturana, não podemos negar as premissas emocionais que dão suporte às ações, em outras palavras, os diferentes mundos que carregamos conosco quando interagimos (MATURANA, 2014, p. 27).

$\mathrm{Na}$ primeira oficina, propusemos o desenvolvimento de um jogo que intitulamos "teia do envolvimento" com o objetivo de disparar questões reflexivas sobre como percebem o constituir da rede. O mesmo jogo foi realizado também na última oficina, pois assim pensamos em observar as transformações na experiência. Com um cordão de nylon, os participantes foram convidados a jogar o rolo um para o outro. Pudemos observar que cada um segurava uma ponta do cordão e, assim, ao mesmo tempo em que autonarravam, uma rede emergia no cruzamento dos fios. O material empregado no jogo fazia surgir uma imagem de rede, ao mesmo tempo em que 
disparava uma autonarrativa livre de cada sujeito sobre seu próprio fazer e a tecitura de rede.

A livre expressão é um conceito essencial na pesquisa que tomamos do trabalho de Nise da Silveira (1992), para quem o afeto catalisador e a livre expressão são cruciais quando desejamos verdadeiramente promover uma aproximação do mundo subjetivo daqueles com quem convivemos. Estávamos ao lado para escutar, observar atentamente, de modo a perceber os movimentos e as construções dos participantes.

Já na segunda oficina, os participantes se puseram a construir pontos importantes para cada um e para o coletivo sobre como promover a aproximação entre os trabalhos na Educação e na Saúde Mental.

Como já mencionado, retomamos ao final da pesquisa empírica a questão: E agora, como percebemos o constituir da rede Educação e Saúde Mental? Assim, procuramos distinguir deslocamentos e transformações na composição de rede entre educação inclusiva e saúde mental, com atenção para as mudanças nas ações dos profissionais.

No quadro 1 , indicamos alguns excertos das autonarrativas no percurso do constituir da rede.

Quadro 1: Explicação do percurso no constituir da rede.

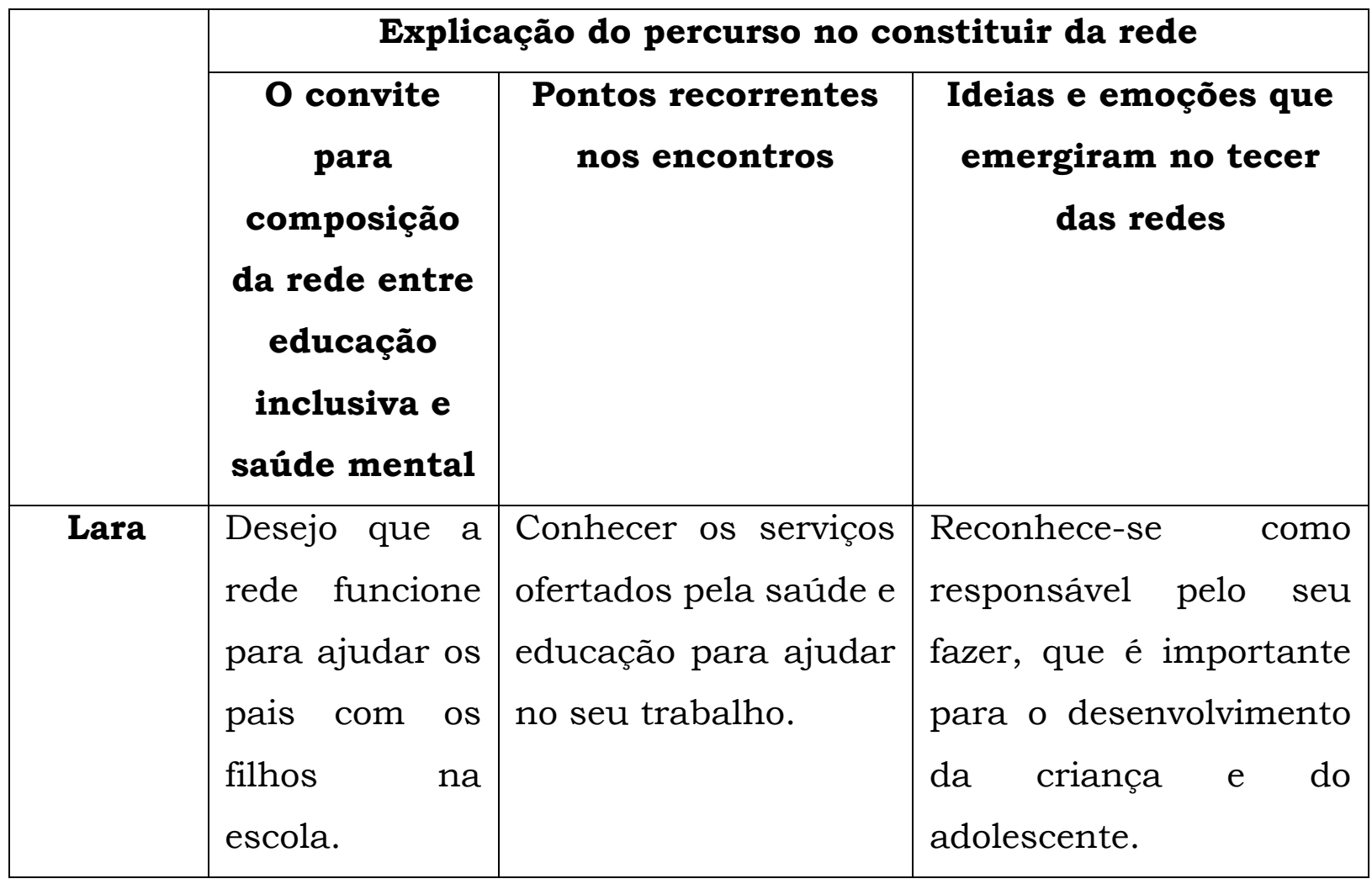




\begin{tabular}{|c|c|c|c|}
\hline Sônia & $\begin{array}{l}\text { Reconhece que } \\
\text { não desenvolve } \\
\text { processos } \\
\text { inclusivos na } \\
\text { formação } \\
\text { continuada } \\
\text { dos } \\
\text { professores. }\end{array}$ & $\begin{array}{l}\text { Caminhar e fazer } \\
\text { junto. As instituições } \\
\text { possuem objetivos } \\
\text { semelhantes, } \\
\text { precisam planejar } \\
\text { juntas. }\end{array}$ & $\begin{array}{l}\text { Ver a rede formada e se } \\
\text { reconhece como } \\
\text { responsável pela } \\
\text { continuidade. } \\
\text { Planeja a construção de } \\
\text { novas ações no } \\
\text { planejamento da } \\
\text { formação continuada do } \\
\text { NTM. }\end{array}$ \\
\hline $\begin{array}{c}\text { Rosinh } \\
\text { a }\end{array}$ & $\begin{array}{l}\text { Desconhece } \\
\text { como essas } \\
\text { redes podem } \\
\text { interagir. }\end{array}$ & $\begin{array}{l}\text { Conhecer e entrelaçar } \\
\text { os serviços, porque } \\
\text { precisa de ajuda. }\end{array}$ & $\begin{array}{l}\text { Se percebe como sujeito } \\
\text { em interação, afetando e } \\
\text { sendo afetado. }\end{array}$ \\
\hline Flor & $\begin{array}{l}\text { Não sabe como } \\
\text { a rede pode se } \\
\text { conectar. } \\
\text { Deseja } \\
\text { aprender } \quad \text { e } \\
\text { conhecer. }\end{array}$ & $\begin{array}{l}\text { Reuniões } \\
\text { conversar e dialogar } \\
\text { sobre as crianças e } \\
\text { adolescentes que } \\
\text { convivem nas redes } \\
\text { Educação e Saúde } \\
\text { Mental. }\end{array}$ & $\begin{array}{l}\text { Reconhece-se como } \\
\text { membro colaborador } \\
\text { que criou vinculos, } \\
\text { sendo responsável por } \\
\text { continuar tecendo a } \\
\text { rede. }\end{array}$ \\
\hline José & $\begin{array}{l}\text { Conhecer as } \\
\text { instituições e } \\
\text { saber como } \\
\text { cuidar dos } \\
\text { usuários. }\end{array}$ & $\begin{array}{l}\text { Precisa conhecer os } \\
\text { equipamentos e o } \\
\text { perfil de cada } \\
\text { atendimento. } \\
\text { Interesse da Gestão. }\end{array}$ & $\begin{array}{l}\text { Encontra-se disponivel } \\
\text { para dar continuidade e } \\
\text { fazer a rede funcionar; } \\
\text { Percebe que o conectar } \\
\text { da rede pode ajudar } \\
\text { ainda mais os pais. }\end{array}$ \\
\hline
\end{tabular}

Fonte: Explicação das pesquisadoras.

A explicação desse percurso foi primordial para visualizarmos as alterações nas ações concretas e nas emoções nos espaços de trabalho. Os profissionais passaram a propor ações conjuntas como efeito dos saberes de cada um, reconhecidos e valorizados na convivência. Processos enativos nos 
permitiram identificar mudanças nos modos de coordenar as condutas no trabalho.

Nas autonarrativas, observamos algumas recorrências em todos os encontros: troca de saberes, busca por parceria e estreitamento de laços. Apresentamos, no quadro 2, as inscrições da profissional do Atendimento Educacional Especializado durante os cinco encontros das oficinas.

Aqui optamos por apresentar uma discussão referida apenas a uma das participantes e, desta forma, fazer movimento de imersão vertical no fazer em rede e no desdobramento das construções de Valéria ${ }^{5}$.

Quadro 2: Inscrições recorrentes da profissional Valéria nos encontros das oficinas.

\begin{tabular}{|c|c|}
\hline \multicolumn{2}{|c|}{ Recorrências nas autonarrativas de uma educadora da educação especial } \\
\hline $\begin{array}{l}1^{\circ} \text { dia } \\
\text { oficina }\end{array}$ & $\begin{array}{l}\text { Trocas é o que mais me interessou, foi essa parceria com o } \\
\text { CAPSi. Nós temos vários alunos que estão no CAPSi e é essa } \\
\text { troca do AEE com o CAPSi que busco (Excerto } \mathrm{n}^{\circ} \text { 03, Valéria - } \\
26 / 09 / 2017 \text { ). }\end{array}$ \\
\hline $\begin{array}{l}2^{\circ} \text { dia } \\
\text { oficina }\end{array}$ & $\begin{array}{l}\text { Pensei na interação, porque um dos serviços do AEE é também } \\
\text { um contato com o CAPSi, com a saúde, é uma de nossas } \\
\text { atribuições. Então, para isso é importante essa interação } \\
\text { porque facilita na construção dos nossos planos e no } \\
\text { encaminhamento dos nossos alunos (Excerto } n^{\circ} 04 \text {, Valéria- } \\
02 / 10 / 2017 \text { ). }\end{array}$ \\
\hline $\begin{array}{l}3^{\circ} \text { dia } \\
\text { oficina }\end{array}$ & $\begin{array}{l}\text { Eu trabalho no AEE e estou aqui para conectar saberes com } \\
\text { vocês (Excerto } \mathrm{n}^{\circ} \text { 05, Valéria - 25/10/2017). }\end{array}$ \\
\hline $\begin{array}{l}4^{\circ} \text { dia de } \\
\text { oficina }\end{array}$ & $\begin{array}{l}\text { Nós percebemos a necessidade de avançarmos mais na } \\
\text { comunicação alternativa, com relação às pranchas de }\end{array}$ \\
\hline
\end{tabular}

\footnotetext{
${ }^{5}$ Nome fictício, assim como todos os nomes no artigo.
} 


\begin{tabular}{|c|c|}
\hline & $\begin{array}{l}\text { comunicação que conhecemos no segundo encontro, e } \\
\text { pensamos numa parceria como NTM, no sentido de orientar a } \\
\text { construção dessas pranchas e, no caso, a fono do CAPSi iria } \\
\text { nos orientar como introduzir essas pranchas no cotidiano } \\
\text { desses alunos (Excerto } \mathrm{n}^{\circ} \text { 06, Valéria, Agnes, Flor - } \\
09 / 11 / 2017 \text { ). }\end{array}$ \\
\hline $\begin{array}{l}5^{\circ} \text { dia de } \\
\text { oficina }\end{array}$ & $\begin{array}{l}\text { Eu me vejo nessa rede como um sujeito em interação com os } \\
\text { demais e também como um aprendiz, né, até mesmo no nosso } \\
\text { próprio AEE, porque diante dos depoimentos, das falas, a } \\
\text { gente sempre vai aprendendo mais com as interações, } \\
\text { especialmente, muito relevante foi o CAPSi como a gente tem e } \\
\text { coloca lá nos planos visitas ao CAPSi, mas na realidade a } \\
\text { gente não tinha essa vivência, era uma coisa muito teórica. E, } \\
\text { nesse momento, a gente teve a oportunidade mesmo de ouvir } \\
\text { as vivências e seria muito importante que isso continuasse, } \\
\text { pelo menos uma vez ao mês, e se estendesse para abranger } \\
\text { aos outros também, não ficar só restrito a esse grupo (Excerto } \\
n^{\circ} 07 \text {, Valéria-24/11/2017). }\end{array}$ \\
\hline
\end{tabular}

Fonte: Arquivos das pesquisadoras.

Observamos a biologia que nos constitui como humanos nesta inseparabilidade entre o conhecer e o viver, com o tecer da rede nas autonarrativas de Valéria: "a gente sempre vai aprendendo mais com as interações".

Compreendemos que a interface com os serviços setoriais da saúde, neste caso desencadeados com a rede CAPSi, é uma experiência já indicada como necessária nos escritos e planos do trabalho no AEE, conforme a Resolução $\mathrm{n}^{\circ} 04$ de 02 de outubro de 2009. Entretanto, a experiência no contexto estudado, segundo Valéria (excerto $\mathrm{n}^{\circ} 07$ ), até aquele momento, "era uma coisa muito teórica". 
O percurso do oficinar de Valéria fez disparar algumas mudanças durante a experiência. Buscamos expor no quadro 3, a partir da explicação da experiência, como Valéria foi se autoconstituindo nesse percurso.

Quadro 3: Caminho explicativo das coordenações de ações no percurso de Valéria.

\begin{tabular}{|c|c|c|}
\hline \multicolumn{3}{|c|}{ Movimento das coordenações de ações } \\
\hline $\begin{array}{c}\text { Percurso Inicial } \\
\text { Desejo }\end{array}$ & $\begin{array}{c}\text { No Trajeto } \\
\text { Ações e Emoções }\end{array}$ & $\begin{array}{c}\text { Percurso Final } \\
\text { Ideias }\end{array}$ \\
\hline $\begin{array}{l}\text { Buscar a troca, realizar } \\
\text { parceria, porque muitos } \\
\text { alunos que atendem } \\
\text { estão no CAPSi, assim } \\
\text { como a necessidade de } \\
\text { inserir ações com a saúde } \\
\text { no plano de ação, } \\
\text { motivos } \\
\text { impulsionaram } \\
\text { participação } \\
\text { pesquisa. }\end{array}$ & $\begin{array}{l}\text { Viver e perceber a } \\
\text { necessidade de } \\
\text { conectar a rede, } \\
\text { promovendo interação } \\
\text { com os profissionais da } \\
\text { saúde para ajudar o } \\
\text { aluno, articulando } \\
\text { ações com o coletivo } \\
\text { CAPSi e AEE. }\end{array}$ & $\begin{array}{l}\text { A necessidade de } \\
\text { continuar aprendendo; } \\
\text { Constituir vivência com } \\
\text { o CAPSi e NTM; } \\
\text { Continuar e ampliar } \\
\text { essa conexão para } \\
\text { todos os profissionais } \\
\text { do AEE. }\end{array}$ \\
\hline
\end{tabular}

Fonte: Explicação das pesquisadoras.

$\mathrm{Na}$ experiência apresentada nas autonarrativas da profissional Valéria, percebemos a inseparabilidade do ser-fazer que nos inspira a refletir sobre o aforismo de Maturana e Varela (2011, p. 31), ao afirmarem: "todo fazer é um conhecer e todo conhecer é um fazer". Os seres vivos são sistemas autônomos e os humanos definem suas condutas em um entrelaçamento de linguagens sustentadas por distintas emoções. As premissas emocionais sustentam modos humanos de conservação da vida em redes de conversação. Podemos reforçar processos competitivos, ou desencadear transformações referidas ao acolhimento, ao aprender e ao cuidar que configuram o trabalho dos profissionais participantes da pesquisa. 
Demoly (2017) refere que a emoção do Amor é um modo de estar com os outros na convivência e que a alegria dos bons encontros produz o tratamento de energia e a potência para agir e promover mudanças no viver. Amor com a letra inicial maiúscula, porque desde a biologia não se trata apenas de um sentimento. Nossa constituição como seres amorosos indica que somos seres que não sobrevivem sem o acolhimento e os cuidados de um outro.

Ao final do estudo nos perguntamos sobre as dificuldades de tecitura de um fazer em rede e discutimos de que é preciso romper com toda uma matriz que se tece no atual contexto social. A competição é impeditiva da tecitura de um trabalho em rede e está na base das estruturas de nossos sistemas educativos, são redes sociotécnicas e poderes sempre atuando.

É importante ressaltar que vamos conservando o mundo que queremos em redes de conversações, são os modos humanos de viver e de conhecer. São escolhas que fazemos. Por exemplo, ao trocar a competição pela colaboração e tecitura de redes, começamos a lidar com as emoções que dão sustentação às ações que promovem processos de aprendizagem no contexto da educação inclusiva e processos de cura e de saúde psíquica no contexto da experiência na saúde mental. Tecemos as redes nas quais queremos viver.

\section{Considerações finais}

A pesquisa teve como objetivo compreender como os profissionais do AEE, NTM e CAPSi experienciam processos de autoconstituição e de composição da/na rede que envolve aprendizagem e cuidado de crianças e adolescentes nos contextos da educação inclusiva e da saúde mental, uma experiência de pesquisa intervenção com oficinas e integração de tecnologias.

Nas oficinas, as autonarrativas e as construções dos profissionais operaram como nós na tecitura de redes entre a educação inclusiva e a saúde mental, criando possibilidades para uma reflexão sobre a aprendizagem e o cuidado na experiência junto a crianças e adolescentes. As oficinas operaram como agentes de problematização. Destaca-se, entre os analisadores produzidos nesse processo, a necessidade e desejo de conhecimento do trabalho desenvolvido nas diferentes instituições e mudanças nas ações cognitivas - ideias, gestos e emoções - na experiência. Pudemos observar a 
composição de redes nas autonarrativas e construções dos participantes e compreendemos que o tecer dessa rede se constituiu no desejo e na necessidade dos profissionais de realizarem parcerias, estudos e aprendizagens. Apontamos, assim, que as redes de conversações e produções realizadas pelos profissionais possibilitaram condições para a emergência de outra configuração coletiva no percurso de realização desta pesquisaintervenção.

Vivenciamos nas oficinas a construção de uma experiência e composição de autonarrativas que permitiram a observação e a explicação sobre como os profissionais atualizam seus modos de constituição nas redes que se tecem entre Educação e Saúde Mental.

O cultivar das autonarrativas como processo metacognitivo implica um fazer que considera a inseparabilidade dos processos de conhecer e autoconstituir-se. Profissionais em processos de individuação realizam alguns deslocamentos no devir, como movimento circular de contínua aprendizagem. Sendo afetados no conviver, fortalecem saberes e experiência construídos nos encontros e qualificam o trabalho com crianças e adolescentes que buscam aprendizagem e cuidado nos espaços da escola e do CAPSi.

$\mathrm{Na}$ construção da pesquisa, caminhamos em congruência com as circunstâncias do nosso viver e fomos encontrando, neste percurso, profissionais interessados em conversar sobre os temas: educação, tecnologia e saúde mental, bem como com o desejo de constituir uma rede que pudesse contribuir com o fazer profissional, considerado como complexo, pois remete ao mundo de múltiplas realidades que precisa de um olhar singular.

A rede foi sendo tecida nos encontros, nas construções e nas autonarrativas que emergiram de questões disparadoras. Os nós experienciados foram trazidos como pontos em destaque e do interesse dos profissionais: conhecer um ao outro, caminhar e fazer juntos, interagir e comunicar, buscar o interesse das gestões da educação inclusiva e da saúde mental, necessidade de encontros e ações intersetoriais, viver/fazer o entrelaçar dos serviços e construir parcerias.

No tecer dos nós, pesquisados e pesquisadoras foram construindo o planejamento das oficinas. Nesse percurso, vivemos movimentos entre 
reflexão e ação no entrelaçar do linguajar, espaço onde articulamos o constituir de uma rede.

As construções envolveram visitas aos ambientes de trabalho e escuta dos saberes uns dos outros, aprendizagem dos materiais e tecnologias que integram no cotidiano e, ainda, conversações sobre percursos de crianças para busca de conhecimento e formas de ação pedagógica e clínica. Observamos que há um grande interesse na tecitura da rede de modo verdadeiro no trabalho dos profissionais.

O conectar da rede Educação e Saúde Mental despertou interesse e desejos nos profissionais de fortalecer o trabalho coletivo com a continuidade dos encontros, o tecer de uma rede que busque conectar saberes e fazeres, pensando sempre no constituir da autonomia dos sujeitos que buscam atendimento pedagógico e clínico nas instituições.

\section{Referências}

AMARANTE, P. O homem e a serpente: outras histórias para a loucura e a psiquiatria. Rio de Janeiro, FIOCRUZ, 2010.

ATLAN, H. Entre o cristal e a fumaça. Rio de Janeiro: Zahar, 1992.

BRASIL. Constituição da República Federativa do Brasil. BRASIL, 1988. Disponivel em: http://www2.camara.leg.br/legin/fed/consti/1988/constituicao-1988-5-out ubro-1988-322142-publicacaooriginal-1-pl.html. Acesso em: 01 dez. 2017.

. Saúde Mental no SUS: Os Centros de Atenção Psicossocial. Ministério da Saúde. Secretaria de Atenção a Saúde Departamento de Ações Programáticas Estratégias. Série F: Comunicação e Educação em Saúde. BRASIL, 2004.

Decreto $n^{\circ}$ 6.571, de 17 de setembro de 2008. Dispõe sobre o Atendimento Educacional Especializado, regulamenta o parágrafo único do art. 60 da lei $\mathrm{n}^{\circ}$ 9.394, de 20 de dezembro de 1996, e acrescenta dispositivo ao 
Decreto $\mathrm{n}^{\mathrm{o}}$ 6.253, de 13 de novembro de 2007. Disponível em: http://www.planalto.gov.br/ccivil_03/_Ato2007-2010/2008/Decreto/D657 1 .htm. Acesso em: 13 set. 2017.

Resolução $n^{\circ}$ 04, de 02 de outubro de 2009. Institui as Diretrizes Operacionais para o Atendimento Educacional Especializado na Educação Básica - Modalidade Educação Especial. MEC: Conselho Nacional de Educação, 2009.

Lei $N^{\circ}$ 13.146, de 6 de Julho de 2015. Dispõe sobre a Lei Brasileira de Inclusão da Pessoa com Deficiência. Disponivel em: $<$ http://www.planalto.gov.br/ccivil_03/_Ato20152018/2015/Lei/L13146.htm>. Acesso em: 04 ago. 2017.

CALLON, M. Por uma nova abordagem da ciência, da inovação e do mercado. O papel das redes sócio-técnicas. In: PARENTE, A. In: (Org.) Tramas da rede. Porto Alegre: Sulina. 2004. p. 64-79, 303p.

DEMOLY, K. R. A.. Linguagens, tecnologias e saúde mental: sobre a atenção e cuidado de si e do outro na convivência. In: Karla Rosane do Amaral Demoly; Maria Aridenise Macena Fontenelle; Maria de Fátima de Lima das Chagas. (Org.). Redes de cuidado e aprendizagem na saúde mental e na educação / organizadoras. 1ed.Ijuí: Editora Unijuí, 2017, v. 1, p. 23-38.

EIZIRIK, M. F. O cuidado com a diferença. Revista Educação Especial (UFSM), v. 30, p. 135-146, 2007.

. Diferença ou exclusão ou ... a gestação de uma mentalidade inclusiva. Revista Educação Especial, BRASIL, v. 4, n. 2, p. 17-23, jul./out. 2008.

FREITAS, C. R. Corpos que não param: criança, TDAH e escola. Tese de Doutorado (Doutorado em Educação) - Programa de Pós Graduação em 
Educação, Universidade Federal do Rio Grande do Sul. Porto Alegre, p. 195. 2011.

MARASCHIN, C. Pesquisar e intervir. In: Psicologia \& Sociedade, v. 16, n. 1. Porto Alegre, 2004.

MATURANA, H. e VARELA, F. J. A árvore do conhecimento: as bases biológicas da compreensão humana. 9.ed. São Paulo: Palas Athenas, 2011.

MATURANA, H. Transformación. Santiago: Dolmen, 1999.

- Emoções e Linguagem na Educação e na Politica. Belo Horizonte: Editora UFMG, 2002.

- Cognição, ciência e vida cotidiana. Belo Horizonte: Editora UFMG, 2006.

A ontologia da realidade. 2 ed. Belo Horizonte: Editora UFMG, 2014.

PARENTE, A. Enredando o pensamento: redes de transformação e subjetividades. In: PARENTE, A. Tramas da rede. Porto Alegre: Sulina. 2004. p. 91-110.

Rede e subjetividade na filosofia francesa contemporânea. In: Revista Eletrônica de Comunicação, Informação \& Inovação em Saúde. Rio de Janeiro, 2007, v. 1, n. 1, p. 101-105. Disponivel em:

$<$ http://www.reciis.cict.fiocruz.br/index.php/reciis/issue / view /9/showToc>. Acesso em: 20/05/2017.

PELlANDA, N. M. C. Maturana \& a Educação. Belo Horizonte: Autêntica Editora, 2009.

SILVEIRA, N. O mundo das imagens. São Paulo: Editora Ática, 1992. 
SIMONDON, G. Du mode d'existence des objets techniques. Paris: Aubier, 1989.

VARELA, F. Conhecer: as ciências cognitivas tendências e perspectivas. Lisboa: Instituto Piaget, 1988. Conhecer. Lisboa: Instituto Piaget, 1990.

VARELA, F.; THOMPSON, E.; ROSCH, E. De cuerpo presente. Barcelona: Editorial Gedisa, 1992. (Livro publicado em português: A Mente Incorporada: Ciências Cognitivas e Experiência Humana. Porto Alegre: Artmed, 2003).

VON FOERSTER, H. Understanding, understanding. New York: Spring, 2003. 